\title{
Identifying English Language Use and Communication Challenges Facing "Entry-Level" Workplace Immigrants in Canada
}

\author{
Liying Cheng ${ }^{1}$ (1) $\cdot$ Gwan-Hyeok $\operatorname{Im}^{1} \cdot$ Christine Doe ${ }^{2} \cdot$ Scott Roy Douglas ${ }^{3}$
}

Published online: 1 September 2020

(C) The Author(s) 2020

\begin{abstract}
Canada has one of the world's largest immigrant populations, with one in five people in Canada born outside the country. Among these immigrants, a great majority started their lives in Canada working in entry-level jobs. This study examined the English language use and communication challenges among these new Canadian immigrants in entry-level workplace settings. Fourteen participants were interviewed. The results showed four distinct patterns of categories: topical knowledge, language knowledge, personal attributes, and communication strategies. These patterns of language use and communication challenges were narrated in each workplace where these immigrants survive and thrive using English. This study addresses the research gap of entry-level workplace immigrants in Canada and provides a nuanced understanding through work and life stories in reference to their English language ability.
\end{abstract}

Key words English language use $\cdot$ Communication challenges $\cdot$ Immigrants $\cdot$ Canada

This study was presented at the 2019 annual conference of the American Educational Research Association (AERA), Toronto, Canada. https://convention2.allacademic.com/one/aera/aera19/index.php?cmd= online_program_direct_link\&program_focus=view_paper\&selected_paper_id=1433534\&sub_action= online_program

Liying Cheng

liying.cheng@quenesu.ca

1 Faculty of Education, Queen's University, Kingston, Ontario K7M 5R7, Canada

2 Faculty of Education, Mount Saint Vincent University, 166 Bedford Hwy, Halifax, NS B3M 2J6, Canada

3 Okanagan School of Education, University of British Columbia, Syilx Okanagan Nation Territory, 3151 EME - 1137 Alumni Avenue, Kelowna, BC V1V 1V7, Canada 


\section{Introduction}

Canada has one of the world's largest immigrant populations, with one in five people born outside the country (Statistics Canada 2016). These immigrants have a diverse range of first language backgrounds other than English or French (the official languages of Canada). According to data from the 2011 National Household Survey (NHS) https://www150.statcan.gc.ca/n1/daily-quotidien/130508/dq130508b-eng.htm, Canada had a total of about $6,775,800$ individuals who arrived in the country as immigrants. They represented $20.6 \%$ of the total population, the highest proportion among the G7 countries. ${ }^{1}$ Within this context, many studies have examined how internationally educated professionals have faced challenges recertifying in their professions in Canada (Lockyer et al. 2010; Myles et al. 2006; Sweetman and Warman 2013). Comparatively fewer research studies have focused on immigrants working in entry-level low-paying workplaces (workplaces for short) (Blanch 2020; Dharssi 2016; Douglas et al. 2020). McCoy and Masuch (2007), while reporting the tough reality faced by many newcomers ${ }^{2}$ in Canada, referred to the term of "entry-level" as "low-status jobs that do not pay well and do not require much formal education or experience" or as "the jobs given to newly qualified but inexperienced workers at varying salary and skill levels" (p. 200). This term is ambiguous yet represents the workplace situation of many newcomers who struggle with the cost of living making minimum wage in workplaces where English is the language of business. The communication demands of these positions are not well understood in Canada even though the country has one of the highest levels of immigrant populations globally. Therefore, understanding how those newcomers who are working in entry-level positions settle is critical for Canada to survive and thrive.

To address the above identified research gap, this study examined English language use and communication challenges among new Canadian immigrants working in low-paying entry-level workplace settings for newcomers (during their first 10 years in Canada in this study). Our study aimed to provide empirical evidence as to what these new Canadian immigrants could do and how well they do in English, including conversations among the immigrants, their managers, and customers at their workplaces.

\section{English Language Ability}

Models of language ability explain what and how language is acquired and used, and the review of these models can help to understand newcomers' English language use and communication challenges in their workplace settings. Definitions of language ability have been conceptualized by looking at what kinds of abilities need to be included in communication. In the beginning, scholars and researchers used the term "communicative competence." Chomsky (1965) viewed that communicative competence was related to an internal state of linguistic knowledge, such as knowledge of lexical, morphological, syntactic, semantic, phonological, and phonetic rules. This view

\footnotetext{
${ }^{1}$ The Group of Seven (G7) refers to the group of seven highly industrialized nations-France, Germany, Italy, the UK, Japan, the USA, and Canada - that hold an annual meeting to foster consensus on global issues like economic growth and crisis management, global security, energy, and terrorism.

2 The term of newcomers refers to recent immigrants to Canada (first 10 years in Canada in this study) and those whose first language is not English in their home countries.
} 
of communicative competence does not include actual, practical use of the knowledge. To respond to this gap, Hymes (1972) expanded the definition of communicative competence to include both linguistic knowledge, including knowledge of how to use language in a social context (sociolinguistic competence), and performance (i.e., actual, practical use of the knowledge), proposing that linguistic theory should be based on practical needs in the real world. One notable aspect of Hymes' (1972) definition is that performance includes not only an ability in the practical sense in any given context, but also non-cognitive factors such as motivation and confidence.

Canale and Swain (1980) expanded and proposed a new theory of communicative competence consisting of three types of competence: grammatical competence, sociolinguistic competence, and strategic competence. Grammatical competence refers to the knowledge of lexical, morphological, syntactic, sematic, and phonological rules. Sociolinguistic competence refers to the knowledge of how to use language in a social context, and strategic competence represents how to deal with a communication breakdown (Canale and Swain 1980). However, a limitation in their framework is that they excluded the ability for use in communicative competence (McNamara 1996). It is important to mention that other expanded notions also exist, e.g., "symbolic competence" emphasizing the creative and polycentric aspects of meaning making (Kramsch 2006) and intercultural communicative competence (Byram 2012, p. 7) as the ability to "communicate and interact successfully with people of other languages and cultures".

Drawing on the work of Canale and Swain (1980), Bachman (1990) provided an explicit, comprehensive model of communicative competence, called communicative language ability (CLA). This model was praised for its depth and breadth (ChalhoubDeville 2003; McNamara 2006), which became the basis for the theoretical framework of the Canadian Language Benchmarks in Canada (Centre for Canadian Language Benchmarks 2013) and has been further developed by Bachman and Palmer (1996, 2010). Within a sociocognitive understanding of how additional languages are acquired, the Bachman and Palmer (2010) model consists of two interrelated components: language knowledge and strategic competence. This conceptualization describes the dimensions of language knowledge and cognitive processes or strategies when using the knowledge in language use situations. Bachman and Palmer's (2010) definition of language ability explains how various factors related to language use interact with each other to result in language ability. In addition, other attributes of language users which also influence their language use, but which are not part of their language ability, are defined as (a) topical knowledge (individual's content and real-world knowledge), (b) personal attributes (age, foreign language attitude, and personality), (c) affective schemata (individual's emotional experiences in a given context), and (d) cognitive strategies (use of problem-solving skills), all of which are peripheral (Bachman and Palmer 2010).

The new immigrants' description of their language use and communication challenges in this study is essential for understanding the communication tasks that they need to complete (i.e., language use) and unfamiliar, unpredictable communication tasks (i.e., communication challenges). In other words, language use represents the communication tasks that new immigrants need to complete to be successful in their jobs, such as taking a food order, negotiating break times with fellow employees, or talking to a customer. Communication challenges may arise when the communication tasks become unpredictable and newcomers are not able to draw on strategies to help them complete the communication tasks successfully. To explain immigrants' language use and their 
communication challenges, previous research studies that investigated immigrants' language use and communication challenges are reviewed in the following section.

\section{English Language Use and Communication Challenges}

In addition to the theoretical guidance stated above, newcomers' English language use and communication challenges can also be explained by Cummins' $(1981,1996)$ concept of basic interpersonal communication skills (BICS). This term describes an aspect of language learners' ability (i.e., interpersonal and conversational skills) before they develop the language skills to deal with academic or cognitively demanding tasks (Cummins 1996). Newcomers who work in entry-level service workplace jobs often need to undertake tasks that draw on BICS-type language communication requiring more interpersonal and conversational skills, such as taking food orders, negotiating break times with fellow employees, or talking to customers. A recent study (Douglas et al. 2020) explores newcomers' language use in similar situations as these identified the importance of the people with whom newcomers interact in relation to successful communication. For the participants in the Douglas et al.'s (2020) study, a variety of factors related to newcomers' interlocutors impeded workplace communication. In particular, when affective tensions were high, other people didn't modify their language, other people had trouble understanding, time pressures were perceived, and participants had negative perceptions of the situation, workplace communication was negatively impacted.

However, on the whole, there has been limited research on the English language use and communication challenges among new Canadian immigrants who make the minimum wage in the workplace. These studies were mostly conducted in professional and academic settings: internationally educated professionals (specifically nurses) (Murray 2012; O’Neill 2011; Sherman and Eggenberger 2008; Tregunno et al. 2009); immigrants in English as a second language programs (Derwing and Rossiter 2002; Kuo 2011); and non-native English-speaking (NNES) international students (Ballard 1996; Barker et al. 1991; Choi 1997; Myles and Cheng 2003; Ramsey et al. 1999; Wan 1992). However, these studies investigated communication challenges only, as part of the difficulties that immigrants or international students experienced in their professional and academic contexts. For example, Sherman and Eggenberger (2008) reported that internationally recruited nurses $(n$ =21) who worked for hospitals across the USA had difficulty in understanding some accents, American idioms, and phrases. In addition, Tregunno et al. (2009) conducted interviews with 20 internationally recruited nurses to investigate difficulties and challenges that the nurses experienced working in Toronto, Canada. When they faced communication challenges, the nurses used humor to change the topic when they did not understand patients, or they paraphrased and repeated what they were saying when they were not understood.

Communication challenges have also been investigated more in-depth in academic contexts. Derwing and Rossiter (2002) surveyed 100 adult immigrants who were enrolled in an English as a second language program at a Canadian university to investigate their perceptions of communication challenges in terms of pronunciation. Out of 100, 42 immigrants stated that their pronunciation mostly caused communication breakdowns, 
and one-third of the 100 stated that people did not understand their speaking often or very often. Furthermore, $11 \%$ of them reported that they had severe problems in pronunciation. When they encountered a communication breakdown, it was reported that they used a variety of communication strategies. The favorite communication strategies they used were paraphrasing (56\%), "self-repetition (28\%), writing/spelling (7\%), volume adjustment (5\%), speaking clearly (3\%), and slowing their speech rate (3\%)" (p.159), including strategies of avoidance and appeals for help. This study shows that developing levels of linguistic knowledge (i.e., pronunciation) can cause communication breakdowns and result in using a variety of communication strategies for successful communication.

In addition, Kuo (2011) surveyed 152 international graduate students at a southern university in the USA to ask about the English communication challenges they encountered. Many types of communication difficulties were reported in and outside the classroom in terms of linguistic and topical knowledge and the interlocutors' attitudes. International students stated that they had challenges in communication with some professors and other American classmates because they spoke too fast and had southern accents. Also, American students did not understand international students' English accents and did not seem to have the tolerance to listen to and talk to them. Furthermore, international students could not understand American students' jokes at a party (Kuo 2011). However, the above survey research studies can have limitations in nuanced understanding of language use and communication challenges. Myles and Cheng (2003) interviewed twelve international graduate students at a Canadian university to investigate difficulties in social and academic situations. Regarding language challenges, they reported that one of the concerns the international graduate students had was their pronunciation when they worked as teaching assistants. Because of their pronunciation, these international students had difficulties getting their messages across in the classroom. Furthermore, pronunciation problems happened in communication with other international graduate students rather than native English speaker graduate students due to their perceived insufficient English proficiency.

Research studies that have been conducted in professional and academic settings consistently show interpersonal communication challenges that have resulted mainly from developing levels of linguistic knowledge (Derwing and Rossiter 2002; Kuo 2011; Myles and Cheng 2003) and topical knowledge (Kuo 2011), as well as the use of communication strategies to deal with the challenges (Derwing and Rossiter 2002; Sherman and Eggenberger 2008). However, there is limited information about the contexts where newcomers use English and encounter communication challenges. Furthermore, newcomers' language use and communication challenges in professional and non-professional settings can be significantly different in terms of the use of vocabulary (e.g., jargon) and modes of communication (e.g., presentations, articles, and reports). Considering the research gap, this study aimed to identify new immigrants' perceived English language use and communication challenges in real-life entry-level workplace settings. Two broad research questions are addressed in this study:

1. How do newcomers in entry-level workplace settings use English for job-related communication?

2. What communication challenges do newcomers encounter and how do they deal with them in the entry-level workplace settings? 


\section{Methods}

To better understand the newcomers' English language use and communication challenges, we turn our attention to examine language ability in language use situations (i.e., what needs to be acquired in what situations) (Niedzielski and Preston 2000; Wilton and Stegu 2011). Drawing on language use in context, this study adopted a qualitative semi-structured interview approach. Semi-structured interviews give flexibility to the participants' responses (Creswell 2008) because they help the researchers to elicit responses to the questions as well as to probe details and discuss issues arising from the responses. In using such a qualitative research method, researchers connected with the participants (Creswell 2014). The researchers in this study have also worked with speakers who speak English as an additional language and have expertise in teaching and doing research with those speakers for many years. This experience has motivated the researchers to understand these speakers' English language use and communications within the workplace context.

\section{Participants}

The participants of this study were newcomers and worked within the entry-level workplace context. These immigrant workers are those who typically make minimum wage in entry-level workplaces in Canada where English is the language of business. Their selfreported English language proficiency ranged from Canadian Language Benchmarks (CLB) 3-6, which is between Stage I Basic (1-4) to Stage II Intermediate (5-8) https://www.clb-osa.ca/benchmarks/overview. Their CELPIP (Canadian English Language Proficiency Index Program celpip.ca/take-celpip/overview/)-General LS (Listening and Speaking) test scores were around 5-6 on average in both listening and speaking. The equivalencies between CLB and CELPIP as well as other language tests are listed in the Government of Canada website, https://www.canada.ca/en/immigrationrefugees-citizenship/corporate/publications-manuals/operational-bulletinsmanuals/standard-requirements/language-requirements/test-equivalency-charts.html.

As illustrated in Table 1, the participants in this study were all Canadian immigrants in various workplaces in and around Kingston and Scarborough, Ontario, Canada. They were listed in the sequence of their interview. In total, 14 people participated in this study. They came from China, Korea, Egypt, Syria, Dominican Republic, Costa Rica, India, Columbia, and Bangladesh. On average, they had 3 years and 9 months ( $\min =1$ year; $\max =10$ years) of residence in Canada and worked as a waitress, hair stylist, cleaner, salesperson, and others. Two of the participants worked as pastors in the local church and they mostly used their first language when working.

\section{Instruments}

The instruments used in this study were two semi-structured interview protocols. The semi-structured interviews were carried out with the participants to elicit information in detail about their English language use communication challenges within the workplace context. We developed the two sequential interviews: interview 1 and interview 2 (see Appendix) based on sociocognitive guiding frameworks and previous research studies (Cheng et al. 2013; Cummins 1981; Roessingh 2006). The first interview was conducted to build rapport and to understand the participants' background information, and the 


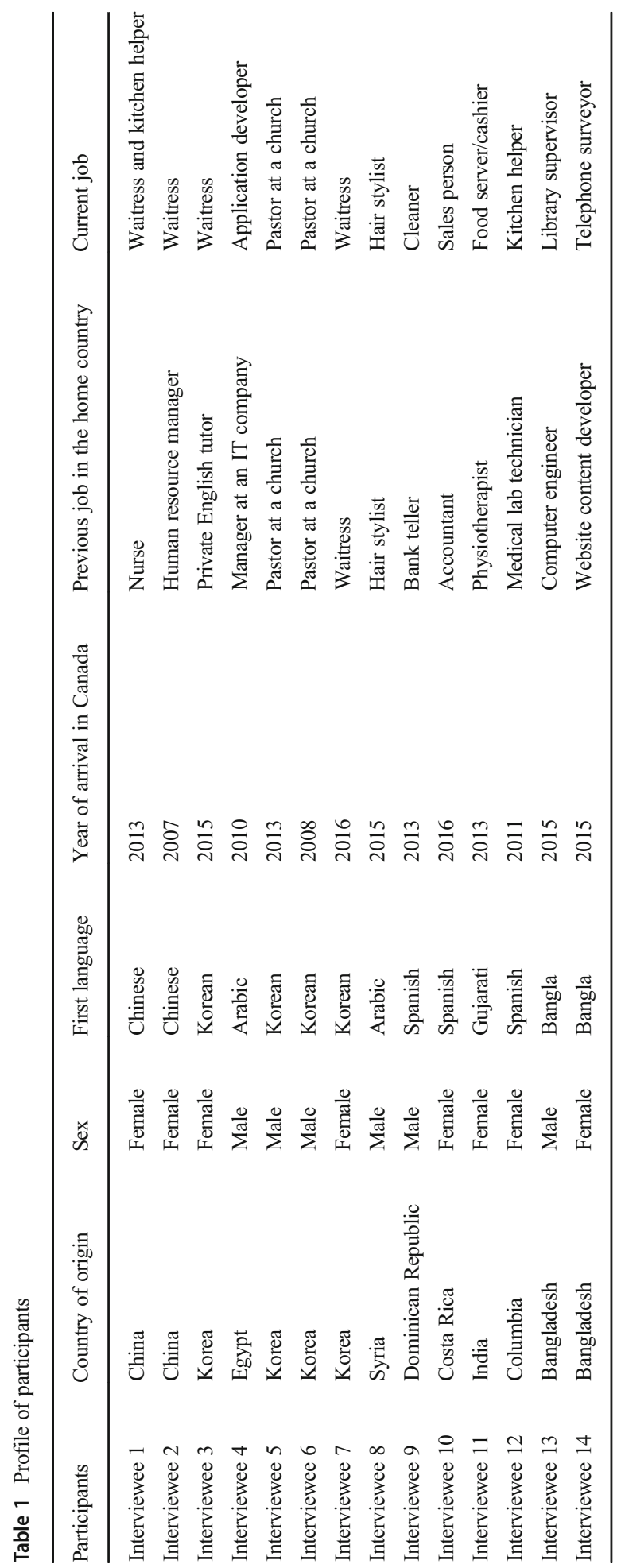


second interview was conducted to delve into their perceptions of language use and communication challenges in their workplaces.

\section{Data Collection}

To recruit participants, we contacted directors and instructors working in English language programs such as the Language Instruction for Newcomers to Canada (LINC), English as a second language (ESL) programs at the local education community center and at an employment agency (i.e., KEYS in Kingston https://www.keys. $\mathrm{ca} /$ ). We also recruited participants using a snowball sampling method (Patton 2002). The data collection was carried out in two phases over a period of several months. In phase 1, the participants were invited for interview 1 to identify the various English language use tasks they were required to complete in their workplace and the kinds of communicative challenges they experienced. In phase 2, the participants took part in interview 2 to elaborate further on their various English language use tasks and communication challenges they faced at their workplaces. Conducting the interviews in two phases was necessary to ensure rich descriptions of workplace communication. This process also accommodated our participants busy time commitments (they often work multiple shifts) and their developing English levels. Each interview lasted between 30 and 60 min and was audio-recorded.

\section{Data Analysis}

Interview data were analyzed using thematic analysis (Braun and Clarke 2006). Braun and Clarke (2006) have provided six steps for qualitative data analysis: "(1) familiarizing yourself with your data; (2) generating initial codes; (3) searching for themes; (4) reviewing themes; (5) defining and naming themes; and (6) producing the report"(p. 39).

Guided by this above analytical framework, we listened to the entire data before coding and then transcribing the interviews as the first step. We transcribed interviews verbatim in Microsoft Word using Adobe Audition version 3, and entered the data from interviews 1 and 2 into QSR Nvivo 12 (www.qsrinternational.com) as the second step. Also, as the second step, we identified possible patterns by taking notes. This process was conducted to generate initial codes in both inductive and deductive ways (i.e., codes that emerged from data and from Bachman and Palmer's (2010) definition of language ability). As the third, fourth, and fifth steps, we had several meetings to first search for themes based on these initial codes and sorted the different codes into potential themes. During subsequent meetings, we refined the themes when some of them did not have enough data to support them by collapsing them into each other or breaking them down into separate themes.

Going through the coding processes, one main theme emerged (i.e., communicative language ability) with two subthemes of communication challenges and coping strategies. Under the two subthemes, four categories were identified as illustrated in Table 2: topical knowledge, language knowledge, personal attributes, and communication strategies. Figure 1 illustrates the relationships between and among the categories. The first three categories are related with communication challenges (subtheme 1), which together lead to communication strategies as coping strategies (i.e., subtheme 2) as experienced by participants. Findings are reported by each category in the "Results" section with salient quotations as a representative example of the category and of the 
Table 2 Four categories and codes

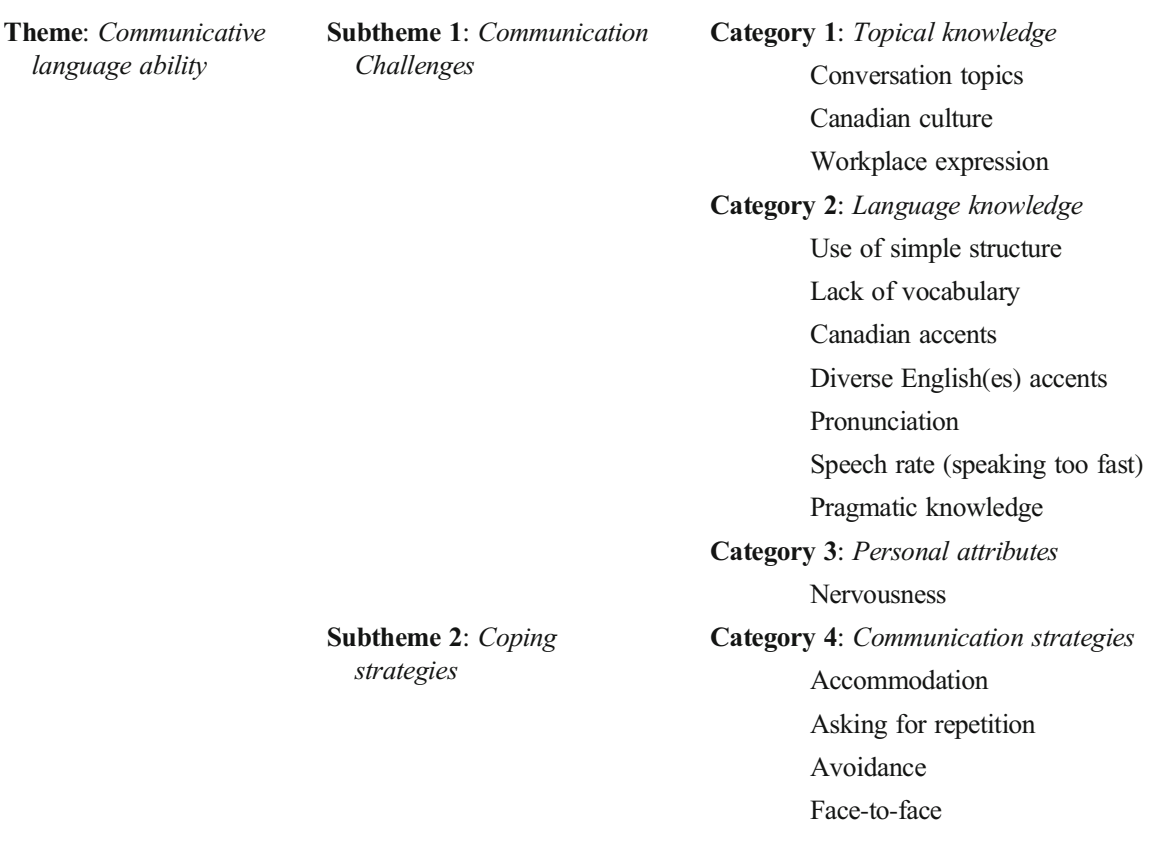

interviewees, a particular subgroup, or a unique comment. Codes within each category are listed as language uses and communication challenges and further identified as predominantly speaking or listening.

Figure 1 illustrates the relationships between communication challenges (i.e., subtheme 1 top left) and coping strategies (subtheme 2 bottom left). The straight black arrows from the categories of topical knowledge on the left, language knowledge in the middle, and personal attributes on the right of the category of communication challenges together lead to communication strategies of the category of coping strategies.

\section{Results}

One main theme (communicative language ability), two subthemes (communication challenges and coping strategies), and four categories were drawn from two sets of interviews obtained from 14 participants. These categories together indicate the perceived English language use and challenges the newcomers encountered in real-life workplace settings. It should be noted that these four categories regarding the newcomers' English language use and communication challenges are not independent but are intertwined with each other. For example, the newcomers' communication challenges may have happened due to their developing vocabulary, unfamiliarity with conversation topics, and the speaker's speech rate. It should also be noted that the newcomers' English use and communication challenges come from both specific work- 


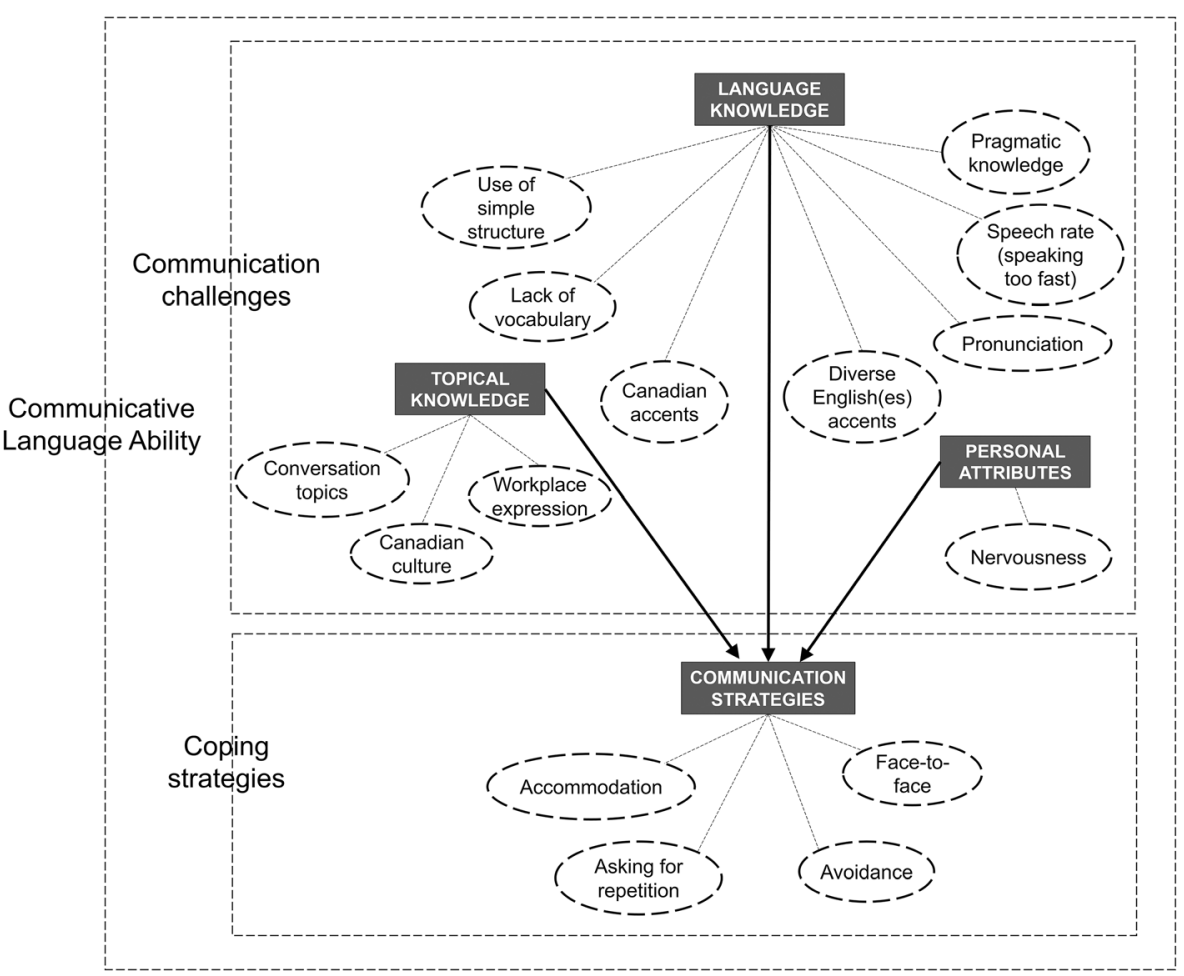

Fig. 1 Illustration of codes and categories for new immigrants' communication challenges and coping strategies. Dotted ovals: codes; black rectangles: categories; straight arrows: relationships between categories

related conversations and casual conversations about family, sports, and the weather with their co-workers and customers to maintain good relationships with customers and their co-workers in their workplace settings. The following sections report the findings based on the four detailed categories of topical knowledge, language knowledge, personal attributes, and communication strategies that emerged from the interviews with the newcomers in this study.

\section{Topical Knowledge}

Topical knowledge refers to an individual's knowledge of content and real-world knowledge (Bachman and Palmer 2010), in this study, in the workplace. This knowledge affects language use, which may contribute to challenges or successes in communication.

The participants in this study commonly stated they faced challenges in listening when they had conversations about unfamiliar topics (i.e., lack of existing knowledge about cultures or the vocabulary/jargon) even though the topics were relevant to their daily lives such as electricity, sports, movies, and expressions used in the community. For example, Interviewee 8 had some conversations about a hockey game with the customers at his workplace. However, he had difficulties in the conversations because he did not have any experience with hockey games. 
You know the big hockey teams, which is like Maple Leafs, Frontenacs Kingston and Maple Leafs [...] anyway you can't join this conversation. I think you had to have experience before [...] they were talking about some stuff. You will be like ah um it's not my place, I am leaving. (Interviewee 8)

In addition to overall communication topics, they also had difficulty understanding what customers or their co-workers asked because they did not know the meaning of terms used in their workplaces, e.g., "double" (two shifts in one workday) and "table setting" (arranging plates, forks, napkins, and others) for Interviewee 1 and "serviette" (a table napkin) for Interviewee 11. When they were familiar with communication topics with customers, on the other hand, they had successful communication in listening and speaking. For example, Interviewee 3 commented that:

When the topic or the word is familiar with me, like Korean food, culture, or my major, I can understand what they are talking to me. For example, last week, an Asian customer asked me about the Korean food, and I told her how to cook it and what the ingredients should be, and she was very happy with that (Interviewee 3)

Similarly, Interviewee 5 perceived that he could achieve successful communication with a clerk at a grocery store because he became familiar with the situation when exposed to it:

I don't speak English many times, I can understand when someone talk to me when I go to a restaurant or a market... like I ask, may I have that? I talk to the cashier... because of the situation. I approach to this situation many times. I go to grocery to buy something every time. (Interviewee 5)

\section{Language Knowledge}

Language knowledge includes two types of knowledge: (a) organizational knowledge in relation to syntax, vocabulary, and phonology and (b) pragmatic knowledge related to knowledge of the language use setting (Bachman and Palmer 2010). We identified situations related to how the newcomers used English and what challenges they encountered through this theme. For example, regarding language use in terms of syntax, Interviewee 4 noted that he used a simple structure when he spoke in English: "For grammar, sometimes I do like to mix tenses. Sometimes I lose the 's' of the third person. I wouldn't like to use too complex grammar. I would like to use simple sentences."

In terms of vocabulary, some participants sometimes faced challenges due to insufficient vocabulary for something they wanted to describe or say to another person. Interviewee 1 stated that:

I want something, the chef wants something, we both are not good at English, he wants something, I also want something, we both don't remember what it is called in English. ... this situation happens a lot. (Interviewee 1) 
Most frequent communication challenges that the newcomers faced were due to phonological aspects of the language such as accents and speech rate. Interviewee 2 stated that she had difficulty taking an order over the phone, specifically checking a customer's street address for food delivery. She had to ask the customer to say their address repeatedly. In addition, Interviewee 3 stated although she did not feel challenges in speaking, but listening is challenging because "there are so many accents depending on their nationalities, like Indian English, Chinese English ... so many Englishes here in Kingston" (Interviewee 3). As an example, Interviewee 13 reported that he felt more comfortable in understanding the English of local Canadian-born people than people from other countries.

I am saying 'come [kəm] back', they say 'come [kom] back' [...] it's challenging. The term we use 'router [rautor]' some people say 'ruter'. So it's really challenging what they are asking for. In different countries, they use different accents. So that is challenging. [...] it is easier to understand Canadian people's accent other than other countries' people. (Interviewee 13)

In addition to challenges in listening, the immigrants' own accents or types of pronunciation might not be intelligible to the customers either. Interviewee 10 frequently experienced customers struggling to figure out what Interviewee 10 asked them: "I need to say them do you need a bag? They don't understand me, a plastic bag. Do you need the receipt - the bill? They don't understand me. They always asked me if I can repeat" (Interviewee 10). Interviewee 3 also had similar challenges when she asked the customers whether they wanted to get the bill:

When I worked at a restaurant, you know, about the time the customers finished their food, I should go to them and give them the bill. Usually I asked them 'Can I get your bill?' You know that they didn't know what I told to them. They always answered me by saying 'Pardon?' 'Sorry?' ... Last week, I asked my Canadian friend what the problem is. She told me not to say 'getyou,' but said 'get-you' that there should be a break between 'get' and 'you.' (Interviewee 3)

In a similar vein, Interviewee 6 often had a hard time because of his pronunciation. He elaborated:

The pronunciation is very difficult, so I speak, like the Panini. But they didn't understand my pronunciation. 'What? What do you mean?'

All participants in this study encountered certain communication challenges when they perceived that native English speakers spoke fast.

Sometimes customers really wanted to talk to me about their garden, their culture, their cars, about the store, about the grocery, so I tried to understand. They speak very fast. I just tried and then I guess the meaning. I don't really understand every sentence, but I tried to understand all the whole, what this means. (Interviewee 2) 
In addition to these challenges related to organizational knowledge, the participants had difficulties in using appropriate language in their workplaces (i.e., pragmatic knowledge). For example, Interviewee 7 reported that she was very confused about asking something and using the appropriate form of addressing someone when she talked to seniors at her workplace.

It is so simple to English speakers. To me, should I say like 'can I' or because they are seniors [older]. So should I say 'may I' or 'could I', 'would you'. Those words. Even some people say 'hi guys'. But, can I say guys to them? Because in Korea, our culture, we cannot just say to grandma and grandpa, 'hey guys how are you doing today?' No, I can't. (Interviewee 7)

In this context, our participant struggled with the language use due to Korean culture and the hierarchy in language use when addressing someone who is older than her.

\section{Personal Attributes}

Personal attributes such as age, sex, nationality, personality, and length of residence affect an individual's language use (Cohen 1994). These attributes are not necessarily part of language ability. In this study, personal attributes are a minor category. However, it was found that they significantly affect individuals' language use. For example, Interviewees 3 and 5, both from Korea, stated that because of their personality, they felt nervous when a stranger or a new customer, especially a Canadian, a fluent user of English, approached them to talk. The nervousness made it difficult for them to understand and speak.

Coz my personality can affect the type of communication. My personality is not that active, a little bit shy. I can easily get hurt. You know, when I stand in front of a native speaker, I am really really nervous. When it is a native Canadian customer, I am kind of shy and that affects my listening and speaking. As for a regular customer, they are very nice and friendly, so when the regular customer came in, I don't have to be scared of him. (Interviewee 3)

\section{Communication Strategies}

Communication strategies are defined as "potentially conscious plans for solving what to an individual presents itself as a problem in reaching a particular communicative goal" (Faerch and Kasper 1983, p. 36). Communication strategies are used when communication problems happen, and the interlocutors find a way to solve (or cope with) the problems using a variety of communication strategies. Participants in this study noted they used a variety of communicative strategies such as asking for repetition (VanPatten and Benati 2010), avoiding the topics that they lacked the necessary vocabulary for or other language skills (Tarone 1981), and preferring face-to-face interaction (Kasper and Kellerman 1997; Tarone 1981) when they encountered communication challenges. In addition, the interlocutors (i.e., fluent users of English) also used accommodation strategies 
(Giles et al. 1991; Zuengler 1991) such as slowing down their speech rate, using simple language, or talking about topics the new immigrants may be familiar with.

Some of the participants stated that those fluent users of English modified their speech by speaking slowly and did not talk about topics they thought the participants may struggle to understand. Through their accommodation, the participants could handle the conversations. Interviewees 2 and 3 stated:

I think when they talked about their travel, bicycle...I think my customers very seldom talk about very difficult things or ask difficult questions - just always very simple things. Just like today I do something, I go to somewhere, so not very difficult for me. I know I don't have very nice English, so they never talk about difficult things for me. (Interviewee 2)

For most of the regular customers at the convenience store, I told them about my poor English. Most of them, at the convenience store, learnt about my poor English, so they speak a little bit more slowly. Normally I can listen what they are saying, especially with the regular customers. (Interviewee 3)

One of the most frequently used strategies was to ask for repetition and slowing down the interlocutors' speech rate when the participants faced language challenges in communication. Interviewee 4 commented, "Like some people, when they tend to speak very fast, I wouldn't comprehend all the words. I have to ask for repetition." Interviewee 3 also stated:

The first time I catch what he told me, I could guess what he was saying but I just, because I was not sure about, so I just asked him to speak slowly. I am not good at English, so could you please speak slowly? Again, two or three times of repetition, so I can get it. (Interviewee 3)

One of the immigrants changed the conversation topic when she encountered unfamiliar topics that she could not handle during a conversation. Interviewee 2 stated:

For example, if customers asked me about sports, or anything. If I understand, I will answer them. If I don't understand them, I just ask them, 'How about your garden?' 'How about your wife?' 'How about your daughter?' (Interviewee 2)

Some of the participants worked at restaurants and had to deal with phone calls for delivery. Phone calls were the most challenging tasks for them to deal with. Thus, they preferred to have face-to-face interactions because they could use body language to replace verbal communication. Interviewee 2 commented, "Because sometimes I serve the customer, some customers just eat at the restaurant. I can serve face-to-face. I can easily understand what they say." 


\section{Discussion and Conclusion}

In this section, findings from this study are discussed according to the two research questions. With regard to the first research question, how newcomers in entry-level workplace settings use English for job-related communication, the participants generally used English daily in conversations with their co-workers, customers, and supervisors about family, sports, food, travel, and movies that required basic interpersonal communication skills (Cummins 1981, 1996) in context-dependent and cognitively undemanding tasks in their workplaces.

To understand the newcomers' English language use more in-depth, our second research question probed, what communication challenges they encounter and how they deal with in the workplace settings. The newcomers mainly had difficulties in communicating with their customers, co-workers, and supervisors due to their lack of topical knowledge, linguistic knowledge, and personal attributes. These findings further build on the previous literature on communication challenges (e.g., Derwing and Rossiter 2002; Douglas et al. 2020; Kuo 2011; Myles and Cheng 2003; Roberts 2010; Sherman and Eggenberger 2008) by providing elaborate communication challenges encountered in the participants' English language use situations.

Overall, the newcomers' English language use and communication challenges categorized by the four categories derived from this study echo and represent Bachman and Palmer's (2010) model of language ability. This model elaborates the conceptual framework for language ability (language knowledge) and related factors (e.g., topical knowledge and personal attributes) leading to strategic competence and cognitive strategies that affect communicative language use (characteristics of the language use task and situation). The four categories are all complex and messy (see Fig. 1). Although these categories may not fully explain the interactions among factors, communication strategies (i.e., strategic competence and cognitive strategies) such as asking for repetition, avoidance of topics, and preference of face-to-face interaction were used by the participants because of personal attributes, their lack of language knowledge, and topical knowledge. Despite this, the findings together represent some of the most typical characteristics of entry-level workplace language use situations.

For example, the communication challenges due to the participants' English accents may be frequently noticed in countries which have a higher population of immigrants, such as Canada. The participants (e.g., Interviewee 3) had difficulties in understanding different English accents of people from a variety of countries, and the participants' accents also affected communication breakdown as well (e.g., Interviewee 6). Considering that the number of immigrants accounts for $20.6 \%$ of the total population in Canada, the interaction among Canadian English accents and various Englishes' accents reflects the actual use of English in everyday life in Canada. In their daily lives, immigrants use English as a lingua franca, which refers to "any use of English among speakers of different first languages for whom English is the communicative medium of choice, and often the only option" (Seidlhofer 2011, p. 7). In this English as a lingua franca context, the use of communication strategies may be one of the most important skills for successful communication in addition to understanding different English accents. In the findings of this study, one of the most frequently used strategies was to ask for repetition (VanPatten and Benati 2010) and accommodations such as 
slowing down the interlocutors' speech rate (Giles et al. 1991; Zuengler 1991). Findings in this study explain the participants' English use and communication challenges in their workplaces.

In the current context of globalization, immigration, and internationalization trend around the world, language socialization in the workplace needs to be re-examined and better understood. Roberts (2010) points out that language socialization in the workplace is "a complex, dynamic setting where migrants experience a double socialization: into the hybrid discourses of the workplace, which all newcomers experience, and into the specific language and cultural practices that realize these discourses" (p. 211). Such socialization practices are evident in our study. The understanding of "double socialization" practices has policy implications for Immigration, Refugees and Citizenship Canada (https://www.canada.ca/en/immigration-refugees-citizenship.html) and local settlement agencies in supporting newcomers to Canada. Most specifically, this understanding has pedagogical implications for LINC instruction (Language Instruction for Newcomers to Canada) (https:/www.canada.ca/en/immigrationrefugees-citizenship/services/new-immigrants/new-life-canada/improve-englishfrench/classes.html), and for workplace training.

This study is one of the few research studies which examined newcomers' English language use and communication challenges in entry-level workplace contexts across Canada. Beyond the policy and instructional implications mentioned above, this study is important in understanding the workplace demands placed on immigrants who use English as an additional language. This is particularly important in the Canadian context where many adult immigrants with professional skills start their new lives in Canada working in these entry-level minimum wage service positions (Blanch 2020; Dharssi 2016) as their professional credentials are not readily recognized (Cheng et al. 2013; McCoy and Masuch 2007). The communication demands of these entry-level positions are not well understood in Canada as yet even though our country has one of the highest levels of immigration globally. However, this study has limitations. To conduct interviews with the participants with different language backgrounds, English was used as a means to communicate during the interviews. Due to the use of English, this study may have limited understandings of the English language use and communication challenges because of participants' developing levels of English language proficiency. We sought to control this limitation by building rapport before and after the interviews, by using two short sets of interviews to help the participants feel comfortable and at ease, and by giving them ample time until they could finish what they wanted to say. At times, we as researchers prompted some of the participants to speak in their first language when we spoke participants' first languages. In addition, we attempted to further examine the relationship between the perceived language use and communication challenges of the study participants, yet due to the limitation of the data, we were not able to delve deeper into such an examination. We further recognize that we examined only a moment of the process of English language use and communication challenges without understanding the past and future. We did not have data on the nature and scope of their English language training either. A longitudinal study would be better in capturing the nuance of language use and challenges reflecting linguistic diversity and reality (Holzinger 2019). Our study was also conducted with immigrants only, without knowing how similar or different native English speakers use English in the workplace. 
Despite the limitations, this study provided the empirical evidence toward understanding how Canadian newcomers in entry-level workplace contexts perceived English language use and communication challenges in their real-life settings. This study contributes by addressing the gap in the limited research on the newcomers' English language use and communication challenges in workplace settings and provides a contextualized personal narratives of newcomers' English language use in the workplace while they navigated the challenges in surviving and thriving in Canada.

Acknowledgments We acknowledge the research funding from Paragon Testing Enterprises which made this study possible. We are grateful to all our participants for making the time to talk with us and for making such a long trip from Kingston to take the CELPIP-General LS Test in Ottawa. We are in awe of their courage and resilience facing the tremendous challenges while surviving, thriving, and contributing to Canada - their new country of residence. We also acknowledge the involvement of Nasreen Sultana in the data collection of this study.

\section{Appendix. Interview protocols}

\section{Interview protocol \#1}

1. When did you come to Canada?

2. What country are you from?

3. What is your first language?

4. What did you do in your own country?

5. Did you come with your family?

6. Have you taken a language test prior to coming to this country? What is your language proficiency level?

7. Where do you work right now? What type of work do you do?

8. Is this your first job in Canada? Does the job require the use of English to communicate with?
a. Co-workers? Topics?
b. Supervisors? Topics?
c. Customers? Topics?

Could you give us some examples?

9. Do you speak English outside the work place? What kind of English do you use outside the workplace? Could you give some examples?

10. Do you speak English with your family members? Please give us some examples?

11. Have you been to a LINC program?

12. Have you ever been assessed for your Canadian Language Benchmark? Do you know your current Canadian Language Benchmark level?

13. [Directions to interviewer: go through the CLB online self-assessment, paper version, with the participant. When looking at the assessment:

a. Ask participants to self-identify where they see their language ability

b. Give examples of language use for the CLB levels] 
14. Thanks for doing the self-assessment. Here is a copy for you. You can see that you are able to reach a CLB X in listening and speaking. [Highlight the final benchmarks] Have a look at the highlighted descriptors over the next few days, and think about what you feel good at when you are using English. Also, think about what language challenges you have at work. Come prepared with some little stories about using language at work. [Put a sticky note with "come prepared with stories of using English at work - both what you are good at and what challenges you.]

\section{Interview protocol \#2}

Based on the findings of the first semi-structured interview, a series of questions are developed to focus on language use and communication challenges when completing the various language use tasks at his or her workplace. For this interview, we want to focus on the strengths and communication challenges faced in the workplace setting.

In the last interview, we asked you to look over the CLB self-assessment that we did and think about the examples of using English at work.

1) Describe stories that you can think of where you were successful speaking English at work.

a) What was the situation/occasion/reason?

b) Who were you speaking with?

c) Why do you think you were successful?

d) Is there a time where you were not successful in a similar situation? If so, what did you do differently this time?

e) Did you ever practice what you were going to say beforehand?

2) Describe stories that you can think of where you had a hard time speaking English at work.

a) What was the situation/occasion/reason?

b) Whom were you speaking with?

c) Why do you think it was difficult?

d) What made it difficult?

e) In the end, what happened? (Was the communication goal achieved?)

f) If you were in the same situation today, what would you do differently?

3) Describe any situation where you felt you could not speak English at work, but wanted to.

a) What was the situation/occasion/reason?

b) Whom were you trying/wanting speaking with?

c) What made it difficult?

d) In the end, what happened? (Alternative strategies used?) 
e) If you were in the same situation today, what would you do differently? (At a trial interview, this question was not quite understood by respondent and has been reworded as follow: "If you have to do it again, what would you do differently?")

4) Describe stories that you can think of where you were successful listening to English at work.

a) What was the situation/occasion/reason?

b) Whom or what were you listening to?

c) Why do you think you were successful?

d) Is there a time where you were not successful in a similar situation? If so, what did you do differently this time?

5) Describe stories that you can think of where you had a hard time listening to English at work.

a) What was the situation/occasion/reason?

b) Whom or what were you listening to?

c) Why do you think it was difficult?

d) What made it difficult?

e) In the end, what happened? (Were they able to ultimately understand the main points?)

f) If you were in the same situation today, what would you do differently?

6) Where do you feel confident when you are using English? What do you feel that you can do well?

7) What language challenges do you face the most when:

- you are greeting customers?

- you are completing a typical transaction with a customer?

- you are interacting with your supervisors?

- you are chatting socially with your co-workers?

- you are working on a work-related task with your co-workers?

- you are on the phone at work with a customer or a supplier?

- you are dealing with a difficult customer?

- you are dealing with outside contractors, such as plumbers, fridge maintenance?

8) Please provide as much detail for the above questions and use concrete examples and wording where possible.

9) Is there anything else you would like to share with us?

Open Access This article is licensed under a Creative Commons Attribution 4.0 International License, which permits use, sharing, adaptation, distribution and reproduction in any medium or format, as long as you give appropriate credit to the original author(s) and the source, provide a link to the Creative Commons licence, and indicate if changes were made. The images or other third party material in this article are included in the article's Creative Commons licence, unless indicated otherwise in a credit line to the material. If material is not included in the article's Creative Commons licence and your intended use is not permitted by statutory 
regulation or exceeds the permitted use, you will need to obtain permission directly from the copyright holder. To view a copy of this licence, visit http://creativecommons.org/licenses/by/4.0/.

\section{References}

Bachman, L. F. (1990). Fundamental considerations in language testing (1st ed.). Oxford: Oxford University Press.

Bachman, L. F., \& Palmer, A. S. (1996). Language testing in practice: designing and developing useful language tests. Oxford, UK: Oxford University Press.

Bachman, L. F., \& Palmer, A. S. (2010). Language assessment in practice: developing language assessments and justifying their use in the real world. Oxford: Oxford University Press.

Ballard, B. (1996). Through language to learning: preparing overseas students for study in Western universities. In H. Coleman (Ed.), Society and the language classroom (pp. 148-169). Cambridge: Cambridge University Press.

Barker, M., Child, C., Gallois, C., Jones, E., \& Callan, V. (1991). Difficulties of overseas students in social and academic situations. Australian Journal of Psychology, 43, 79-84. https://doi.org/10.1080 /00049539108259104.

Blanch, N. (2020, February 17). 'There is not opportunities for you': immigrants want more than entry-level jobs. $C B C$ news. https://www.cbc.ca/news/canada/new-brunswick/juliana-walckoff-immigrant-dieppejobs-mayors-moncton-riverview-1.5460728.

Braun, V., \& Clarke, V. (2006). Using thematic analysis in psychology. Qualitative Research in Psychology, 3(2), 77-101. https://doi.org/10.1191/1478088706qp063oa.

Byram, M. (2012). Language awareness and (critical) cultural awareness relationships, comparisons and contrasts. Language Awareness, 21(1), 5-13. https://doi.org/10.1080/09658416.2011.639887.

Canale, M., \& Swain, M. (1980). Theoretical bases of communicative approaches to second language teaching and testing. Applied Linguistics, 1(1), 1-47.

Centre for Canadian Language Benchmarks. (2013). Theoretical framework for the Canadian Language Benchmarks and Niveaux de Compétence Linguistique Canadiens. Ottawa: Centre for Canadian Language Benchmarks.

Chalhoub-Deville, M. (2003). Second language interaction: current perspectives and future trends. Language Testing, 20(4), 369-383. https://doi.org/10.1191/02655322031t264oa.

Cheng, L., Spaling, M., \& Song, X. (2013). Barriers and facilitators to professional licensure and certification testing in Canada: perspectives of internationally educated professionals. Journal of International Migration and Integration, 14(4), 733-750. https://doi.org/10.1007/s12134-012-0263-3.

Choi, M. (1997). Korean students in Australian universities: intercultural issues. Higher Education Research and Development, 16, 263-281. https://doi.org/10.1080/0729436970160302.

Chomsky, N. (1965). Aspects of the theory of syntax. Cambridge: MIT Press.

Cohen, A. D. (1994). Assessing language ability in the classroom (2nd ed.). Boston: Heinle and Heinle.

Creswell, J. W. (2008). Educational research: planning, conducting, and evaluating quantitative and qualitative research. Boston: Pearson Education.

Creswell, J. W. (2014). Research design: qualitative, quantitative, and mixed methods approaches (4th ed.). Los Angeles: Sage.

Cummins, J. (1981). The role of primary language development in promoting educational success for language minority students. In California State Department of Education (Ed.), Schooling and language minority students: a theoretical framework (pp. 3-49). Los Angeles: Evaluation, Dissemination and Assessment Center. http://www.eric.ed.gov/PDFS/ED249773.pdf. Accessed 1 September 2019.

Cummins, J. (1996). Negotiating identities: education for empowerment in a diverse society (1st ed.). Walnut: California Association for Bilingual Education.

Derwing, T. M., \& Rossiter, M. J. (2002). ESL learners' perceptions of their pronunciation needs and strategies. System, 30, 155-166. https://doi.org/10.1016/S0346-251X(02)00012-X.

Dharssi, A. (2016). Skilled immigrants wasting their talents in Canada. Calgary Herald. https://calgaryherald. com/news/national/skilled-immigrants-wasting-their-talents-in-canada/. Accessed 1 September 2019

Douglas, S. R., Doe, C., \& Cheng, L. (2020). The role of the interlocutor: factors impeding workplace communication with newcomers speaking English as an additional language. Canadian Modern Language Review, 76(1), 31-49. https://doi.org/10.3138/cmlr.2018-0161. 
Faerch, C., \& Kasper, G. (1983). Plans and strategies in foreign language communication. In C. Faerch \& G. Kasper (Eds.), Strategies in interlanguage communication (pp. 20-60). New York: Longman.

Giles, H., Coupland, J., \& Coupland, N. (1991). Context of accommodation: developments in applied sociolinguistics. Cambridge: Cambridge University Press.

Holzinger, C. (2019). 'We don't worry that much about language': street level bureaucracy in the context of linguistic diversity. Journal of Ethnic and Migration Studies., 46, 1792-1808. https://doi.org/10.1080 /1369183X.2019.1610365.

Hymes, D. H. (1972). On communicative competence. In J. B. Pride \& J. Holmes (Eds.), Sociolinguistics (pp. 269-293). Harmondsworth: Penguin Books.

Kasper, G., \& Kellerman, E. (1997). Communication strategies: psycholinguistic and sociolinguistic perspectives. New York: Longman.

Kramsch, C. (2006). From communicative competence to symbolic competence. The Modern Language Journal, 90(2), 249-252.

Kuo, Y.-H. (2011). Language challenges faced by international graduate students in the United States. Journal of International Students, 1(2), 38-42 http://ssrn.com/abstract=1958387. Accessed 1 September 2019.

Lockyer, J., Fiddler, H., de Gara, C., \& Keefe, J. (2010). Learning to practice in Canada: the hidden curriculum of international medical graduates. Journal of Continuing Education in the Health Professions, 30(1), 37-43. https://doi.org/10.1002/chp.20054.

McCoy, L., \& Masuch, C. (2007). Beyond "entry-level” jobs: immigrant women and non-regulated professional occupations. Journal of International Migration and integration, 8(2), 185-206. https://oi. org/10.1007/s12134-007-0013-0.

McNamara, T. F. (1996). Measuring second language performance. New York: Longman.

McNamara, T. F. (2006). Validity in language testing: the challenge of Sam Messick's legacy. Language Assessment Quarterly, 3(1), 31-51. https://doi.org/10.1207/s15434311laq0301_3.

Murray, N. (2012). A report on a pilot English language intervention model for undergraduate trainee nurses. Journal of Academic Language and Learning, 6(1), A48-A63 http://journal.aall.org.au/index. php/jall/article/view/135. Accessed 1 September 2019.

Myles, J., \& Cheng, L. (2003). The social and cultural life of non-native English speaking international graduate students at a Canadian university. Journal of English for Academic Purposes, 2(3), 247-263. https://doi.org/10.1016/S1475-1585(03)00028-6.

Myles, J., Cheng, L., \& Wang, H. (2006). Teaching in elementary school: perceptions of foreign-trained teacher candidates on their teaching practicum. Teaching and Teacher Education, 22(2), 233-245. https://doi.org/10.1016/j.tate.2005.09.001.

Niedzielski, N. A., \& Preston, D. R. (2000). Folk linguistics. Berlin: Mouton de Gruyter.

O'Neill, F. (2011). From language classroom to clinical context. The role of language and culture in communication for nurses using English as a second language. International Journal of Nursing Studies, 48, 1120-1128. https://doi.org/10.1016/j.ijnurstu.2011.02.008.

Patton, M. Q. (2002). Qualitative research and evaluation methods (3rd ed.). Los Angeles: Sage.

Ramsey, S., Barker, M., \& Jones, E. (1999). Academic adjustment and learning processes: a comparison of international and local students in first-year university. Higher Education Research and Development, 18, 129-144. https://doi.org/10.1080/0729436990180110.

Roberts, C. (2010). Language socialization in the workplace. Annual Review of Applied Linguistics, 30, 211227. https://doi.org/10.1017/S0267190510000127.

Roessingh, H. (2006). BICS-CALP: an introduction for some, a review for others. TESL Canada Journal, 23(2), 91-96 http://www.teslcanadajournal.ca/index.php/tesl/article/viewFile/57/57. Accessed 1 September 2019.

Seidlhofer, B. (2011). Understanding English as a lingua franca. Oxford: Oxford University Press.

Sherman, R., \& Eggenberger, T. (2008). Transitioning internationally recruited nurses into clinical practice. Journal of Continuing Education in Nursing, 39(12), 535-544.

Statistics Canada. (2016). Census profile, 2016 censure. https://www12.statcan.gc.ca/censusrecensement/2016/dp-pd/prof/index.cfm?Lang=E. Accessed 1 September 2019.

Sweetman, A., \& Warman, C. (2013). Canada's immigration selection system and labour market outcomes. Canadian Public Policy/Analyse De Politiques, 39, S141-S160 http:/www.jstor.org/stable/23594762. Accessed 1 September 2019.

Tarone, E. (1981). Some thoughts on the notion of communication strategy. TESOL Quarterly, 15(3), 285295. https://doi.org/10.2307/3586754.

Tregunno, D., Peters, S., Campbell, H., \& Gordon, S. (2009). International nurse migration. U-turn for safe workplace transition. Nurse Inquiry, 16, 182-190. https://doi.org/10.1111/j.1440-1800.2009.00448.x. 
VanPatten, B., \& Benati, A. G. (2010). Key terms in second language acquisition (1st ed.). New York: Continuum.

Wan, T. (1992). Academic stress of international students attending U.S. universities. Research in Higher Education, 33, 607-623. https://doi.org/10.1007/BF00973761.

Wilton, A., \& Stegu, M. (2011). Bringing the 'folk' into applied linguistics: an introduction. AlLA Review, 24, 1-14. https://doi.org/10.1075/aila.24.01wil.

Zuengler, J. (1991). Accommodating in native-nonnative interactions: going beyond the what to the why in second-language research. In H. Giles, J. Coupland, \& N. Coupland (Eds.), Contexts of accommodation: developments in applied sociolinguistics (pp. 223-244). Cambridge: Cambridge University Press.

Publisher's Note Springer Nature remains neutral with regard to jurisdictional claims in published maps and institutional affiliations. 